\title{
Perbedaan Literasi (Pengetahuan dan Pengambilan Keputusan) tentang Kanker melalui Metode Ceramah dan Konseling pada Masyarakat
}

\author{
Laili Rahayuwati $^{\mathrm{a}}$, Kusman Ibrahim ${ }^{\mathrm{a}}$, Ikeu Nurhidayah ${ }^{\mathrm{a}}$, Dyah Setyorini ${ }^{\mathrm{a}}$ \\ ${ }^{a}$ Fakultas Keperawatan Universitas Padjadjaran, Bandung, Indonesia \\ e-mail: laili.rahayuwati@unpad.ac.id
}

\begin{abstract}
The high prevalence and incidence of breast cancer in Indonesia remains a disheartening issue, for it has turned out to be a threat for the quality of Indonesian women's life. The aim of this study is to develop the communities' literacy to have more concern to prevent the health problems especially cancer that has spreading increasingly widespread in the community. The health education through lecture, discussion, and councelling of cervical cancer were conducted in this study to increase literacy on cancer. The result showed that the characteristic of women who attended the counseling and early detection examination of cervical cancer was 46 - 55 years old as many as 23 respondents (38.33\%). This suggests that adult women are more interested than others. In the education level showed that the high school level were 26 respondents (43.3\%). The result of test of this study found that 29 respondents (48.33\%) were high score of pre-test result while in the post-test result found 23 respondents (38.33\%) were medium score. The different scores between the pre-test and post-test because of various factors. The activity of health education and learning intensively to the community has positive impact, the public becomes awareness on information, increase knowledge on cervical cancer, particularly in the cancer prevention and improve the quality of life among patients with cancer.
\end{abstract}

Keywords: cervical cancer, health education, literacy

\begin{abstract}
Abstrak
Prevalensi dan insidensi yang tinggi terhadap kanker payudara merupakan masalah yang mengancam kualitas wanita Indonesia. Tujuan dari penelitian adalah untuk mengembangkan kemampuan literasi masyarakat dalam hal menjaga masalah kesehatan terutama yang berkaitan dengan kanker dan peningkatan jumlah penderita di masyarakat. Pendidikan kesehatan melalui ceramah, diskusi dan konseling dilakukan dalam penelitian ini untuk meningkatkan kemampuan litarsi tentang kanker. Hasil penelitian ini didapatkan bahwa karakteristik usia wanita yang menghadiri acara penyuluhan dan pemeriksaan dini Ca Serviks adalah usia 46-55 tahun sebanyak 23 orang (38,33\%). Hal ini menunjukkan bahwa wanita dewasa lebih tertarik dibandingkan usia wanita yang lebih muda. Untuk pendidikan terakhir yang terbanyak adalah lulusan SMA sebanyak 26 orang (43,3\%). Adapun hasil pretest pengetahuan, didapatkan sebanyak 29 wanita memiliki skor baik $(48,33 \%)$. Sedangkan hasil posttest terjadi kenaikan pada skor sedang yaitu 23 orang $(38,33 \%)$. Hal ini menunjukkan adanya penurunan nilai dari pretest dan posttest, dikarenakan dengan berbagai faktor dilapangan. Dari hasil kegiatan setelah dilakukan Pendidikan kesehatan dengan metode ceramah dan konseling pada masyarakat, masyarakat menjadi lebih banyak tahu mengenai informasi kanker serviks dimasyarakat. Hasil pengabdian kepada masyarakat ini diharapkan dapat menghasilkan masyarakat
\end{abstract}


yang memiliki pengetahuan tentang tindakan preventif penyakit kanker dan peningkatan kualitas hidup pada pasien penderita kanker.

Kata kunci: deteksi dini, kanker serviks, penyuluhan

\section{PENDAHULUAN}

Di Indonesia, prevalensi penyakit dan kematian pada beberapa kasus masih tinggi, terutama yang berkaitan dengan tumor ganas atau kanker. Untuk kasus penyakit di kalangan perempuan, kanker payudara menempati tempat tertinggi jumlah insidensinya, terutama di 7 negara seperti: Indonesia, Jepang, Malaysia, Filipina, Singapura, Srilanka dan Taiwan. Berkaitan dengan angka kesakitan dan kematian pada kanker, WHO (2013) menyatakan secara spesifik bahwa sekitar 508.000 perempuan meninggal karena kanker payudara di tahun 2011. Kanker payudara itu sendiri, umumnya terjadi pada kelompok wanita pasca menoupause, meskipun saat ini banyak ditemukan pada usia yang sangat muda, seperti kurang dari 25 tahun, dan sedikit kejadian yang dialami pada pria. Sebagai tambahan, kanker payudara akan berpengaruh terhadap keberadaan dan kesejahteraan seorang wanita tidak saja secara fisik, namun juga emosional, psikologis, sosial dan spiritual, terlebih lagi pada wanita usia reproduktif, dan posisinya sebagai perempuan, istri maupun ibu. Meskipun kanker payudara dikenal sebagai penyakit yang umumnya terjadi di negara-negara berkembang atau sudah maju, namun dari sekitar $50 \%$ pasien kanker payudara, sejumlah 58\% kematian akibat kanker payudara justru terjadi terjadi di negaranegara sedang berkembang (Cancer Research UK, 2001; Globocan, 2008).

Kecenderungan yang mencolok di negara Asia dimana jumlah kematian pertahun karena kanker payudara pada tahun 2002 sebesar 3,5 juta dan diperkirakan akan meningkat menjadi 8,1 juta pada tahun 2020. Bahkan, data prevalensi di Indonesia menunjukkan, sekitar 1000 kasus kanker payudara ditemukan dari sekitar 100.000 jumlah penduduk. Selain itu, berdasarkan Sistem Informasi Rumah Sakit (SIRS) di Indonesia, jumlah pasien kanker sesuai dengan urutan terbanyak adalah: kanker payudara sejumlah 12.014 (28.7\%), kanker leher rahim sejumlah 5.349 (12.8\%), leukimia sejumlah 4.342 (10.4\%), lymphoma $3.486(8.3 \%)$ dan kanker paru-paru 3.244 (7,8\%).

Prevalensi dan insidensi kanker payudara yang cukup tinggi di Indonesia sangat memprihatinkan karena hal ini merupakan ancaman terhadap kualitas hidup perempuan Indonesia.. Terlebih lagi, pasien dan keluarga seringkali menghadapi masalah yang berkaitan dengan pengenalan terhadap kanker payudara sejak dini maupun kondisi lanjut, selain itu mereka juga sering kesulitan untuk memutuskan pilihan terapi, apakah menggunakan terapi modern ataupun lainnya, seperti terapi komplementer. Sebagaimana yang kita ketahui bahwa Indonesia dikenal sebagai negara sedang berkembang yang mempunyai jenis pelayanan kesehatan bersifat plural medical systems baik di lihat dari sudut pandang institusi maupun praktisinya.

Berkaitan dengan pelayanan kesehatan yang dipilih oleh pasien, data dari wawancara dengan perawat di Rumah Sakit Hasan Sadikin Bandung menunjukkan, bahwa hampir $70 \%$ pasien dengan kanker payudara mengalami putus kemoterapi dan banyak pasien kanker payudara tidak melakukan kemoterapi pra bedah setelah didiagnosis terkena kanker payudara stadium awal dan lebih memilih perawatan alternatif. Selanjutnya, pada survei lanjutan yang melibatkan 36 pasien kanker payudara mengungkapkan bahwa 
terdapat beberapa motivasi pasien dalam menggunakan terapi komplementer atau alternatif yaitu: membantu tubuh dalam proses penyembuhan (75\%), meningkatkan sistem kekebalan tubuh (56\%), dan merasa berbuat sesuatu dalam terapinya (56\%). Selain itu, sebanyak $88 \%$ responden menyatakan menggunakan terapi komplementer atau alternatif dengan melakukan terapi medis dalam waktu yang sama.

Meninjau permasalahan jumlah peningkatan pasien kanker payudara, pemahaman dan konsep pencegahan tentang kanker, penentuan atau pengambilan keputusan dalam pengobatan kanker, diperlukan suatu kajian di masyarakat tentang dasar pengetahuan dan proses intervensi yang dilakukan dalam meningkatkan kemampuan literasi tentang kanker.

Beberapa jenis metode pengajaran dalam pendidikan kesehatan dimungkinkan akan mampu memberikan informasi dan meningkatkan literasi di komunitas, berdasarkan hasil kajian Susilo (2011) menjelaskan bahwa dalam melakukan pendidikan kesehatan untuk mencapai tujuan yang diharapkan maka salah satunya dengan cara menggunakan metode pengajaran. Penggabungan kombinasi antara metode ceramah dan konseling bertujuan saling melengkapi kekurangan pada metode lainnya. Metode ceramah merupakan metode pendidikan yang sudah sejak lama digunakan untuk menyampaikan ide, gagasan, informasi baru terhadap sasaran yang diinginkan. Adapun konseling berutujuan untuk memberikan pemahaman secara lebih intens dan bersifat khusus sesuai kebutuhan indvidu. Adapun tujuan penelitian ini adalah untuk mendapatkan hasil tentang perbedaan pengethuan setelah mendapatkan kedua metode gabungan pendidikan kesehatan, yaitu ceramah dan konseling tentang kanker.

\section{METODE}

Desain dalam penelitian ini menggunakan desain penelitian pre eksperimen, tanpa menggunakan kelompok kontrol atau pembanding, dengan tujuan hanya untuk melihat perbandingan atau perbedaan pengetahuan dengan metode kombinasi yang diberikan. Populasi dalam penelitian ini adalah masyarakat Kecamatan Arjasari, Kabupaten Bandung. Instrumen yang digunakan dalam penelitian ini adalah instrument pengetahuan tentang kanker sejumlah 40 pernyataan. Konstruk instrumen pada penelitian ini menggunakan uji validitas dan reliabilitas terpakai dengan pengujian coefficient alpha didapatkan 0,96, sedangkan pengujian test-retest correlation didapatkan 0,92. Uji konten pakar dilakukan untuk memberikan pertanyaan yang spesifik bias dipahami masyarakat.

Teknik pengambilan sampel dalam penelitian ini menggunakan purposive sampling, yaitu berdasarkan kedatangan para ibu-ibu yang ada di Kecamatan Arjasari, Kabupaten Bandung, sejumlah 60 responden.

\section{HASIL}

Dari hasil penelitian di Kecamatan Arjasari didapatkan hasil sebagai berikut:

\section{A. Karakteristik Masyarakat}

Karakteristik Masyarakat Desa Arjasari, merupakan sebuah desa yang terletak di Kecamatan Arjasari, Kabupaten Bandung, Jawa Barat. Desa Arjasari terdiri dari 5 dusun yang terbagi menjadi 15RW. Luas desa sebesar 70.862 ha dengan batas wilayah sebelah barat adalah lebak wangi, sebelah timur adalah Desa Pinggirsari, sebelah utara adalah warga Guyu dan sebelah selatan adalah Desa Baros. Desa Arjasari memiliki luas lahan pertanian seluas 597 ha, lahan sawah seluas 335 hs dan lahan perhutani seluas 150 ha. Desa Arjasari dikenal dengan desa yang kaya akan kekayaan alamnya serta potensi sumber daya alam yang belum tersentuh oleh berbagai pihak khususnya 
investor-investor yang kerap mencari lahan untuk kemudian dibudidayakan.

Salah satu visi dan misi dari Desa Arjasari adalah dalam hal pembangunan baik pembangunan secara lahan atau wilayah dan pembangunan masyarakat yang maju. Pembangunan masyarakat bisa salah satunya dengan membangun sistem kesehatan masyarakat Desa Arjasari. Masyarakat Desa Arjasari memiliki banyak potensi yang bisa dikembangkan dari mulai dari pertanian, peternakan hingga home industry yang saat ini banyak dilakukan masyarakat. Oleh karena itu, masyarakat Desa Arjasari kerap melupakan kesehatan mereka. Permasalahan kesehatan pada masyarakat Desa Arjasari dari hasil pengamatan kegiatan KKNM Universitas Padjadjaran yang dilakukan pada tahun 2015 adalah kurangnya kesadaran mengenai kesehatan serta kebersihan lingkungan yang tidak menjadi perhatian utama masyarakat desa yang juga didukung dengan sulitnya akses menuju pelayanan kesehatan. Selain itu juga terdapat beberapa penyakit yang sering diderita oleh masyarakat Desa Arjasari seperti hipertensi, TBC, infeksi saluran pernafasan akut, dan kanker.

Karakteristik masyarakat yang mengikuti kegiatan Pendidikan kesehatan Arjasari dapat digambarkan pada tabel 1 . berikut ini

Tabel 1. Karakteristik Peserta Penyuluhan Desa Arjasari

\begin{tabular}{clll}
\hline No & \multicolumn{1}{c}{ Karakteristik } & f & \multicolumn{1}{c}{$\%$} \\
\hline 1. & Usia Masyarakat & & \\
& $-18-25$ & 4 & 6,67 \\
& $-\quad 26-35$ & 4 & 6,67 \\
& $-\quad 36-45$ & 19 & 31,67 \\
& $-46-55$ & 23 & 38,33 \\
& $-\quad 56-65$ & 6 & 10 \\
& $-\quad>65$ & 4 & 6,67 \\
\hline 2. & Pendidikan & & \\
& - SD & 17 & 28,3 \\
& - SMP/SLTP & 11 & 18,3 \\
& - SMA/SLTA & 26 & 43,3 \\
& - Diploma/Sarjana & 6 & 10 \\
& & &
\end{tabular}

Pada tabel 1 terlihat bahwa karakteristik usia wanita yang menghadiri acara Pendidikan kesehatan dihadiri oleh usia dengan rentang $46-55$ tahun sebanyak 23 orang atau $38,33 \%$. Jumlah besar selanjutnya dihadiri oleh wanita usia 36 - 45 tahun sebanyak 19 orang atau $31,67 \%$. Hal ini menunjukkan bahwa wanita usia dewasa lebih banyak yang tertarik dibanding dengan usia rentang lainnya yang lebih muda. Adapun untuk untuk tingkat pendidikan terakhir yang terbanyak yang datang adalah lulusan SMA/SLTA sebanyak 26 orang atau 43,3\%. Peringkat kedua diduduki oleh lulusan SD sebanyak 17 orang atau $28,3 \%$.

Hasil pretest dan posttest masyarakat yang mengikuti Pendidikan kesehatan di Desa Arjasari dapat digambarkan pada tabel 2 berikut ini :

Tabel 2. Hasil Pretest dan Posttest Peserta Pendidikan Kesehatan

\begin{tabular}{ccccc}
\hline \multirow{2}{*}{ Kategori } & \multicolumn{2}{c}{ Frekuensi (n) } & \multicolumn{2}{c}{$\begin{array}{c}\text { Persentase } \\
(\%)\end{array}$} \\
\cline { 2 - 5 } & Pre- & Post- & Pre- & Post- \\
& Test & Test & Test & Test \\
\hline Tinggi & 29 & 15 & 48,33 & 25 \\
Sedang & 26 & 42 & 28,33 & 38,33 \\
Rendah & 5 & 3 & 8,33 & 5 \\
\hline
\end{tabular}

Pada tabel 2 terlihat hasil dari dilakukannya pretest dan posttest pada peserta yang hadir. Hasil didapatkan ada sebanyak 29 orang memiliki score tinggi pada pretest atau sebanyak 48,33\%. Sedangkan pada hasil posttest didapatkan ada 23 orang yang memiliki score dengan kategori sedang atau sebanyak $38,33 \%$. Hal ini menunjukkan adanya penurunan nilai dari pretest dan posttest pada kategori tinggi, namun terjadi penambahan jumlah pada kategori sedang. Ada beberapa kemungkinan penyebab faktor-faktor tersebut dikarenakan dengan berbagai kondisi di lapangan. Antara lain, gangguan konsentrasi ibu-ibu karena posttest 
dilakukan sudah menjelang siang, dan distraksi ruangan atau fasilitas yang digunakan kurang memadai untuk kegiatan ceramah dan konseling.

\section{PEMBAHASAN}

Hasil analisis deskriptif perbandingan dengan menggunakan tabel 2 x 2 menunjukkan bahwa karakteristik masyarakat yang mengikuti penyuluhan dan deteksi dini kanker serviks lebih banyak pada usia 46 - 55 tahun yaitu sebanyak 23 masyarakat atau $38,33 \%$. Berdasar evaluasi proses selama pendidikan kesehatan berlangsung menunjukkan bahwa masyarakat yang lebih antusias terhadap pendidikan kesehatan adalah wanita yang dewasa. Sementara wanita di usia produktif dibawah 46 tahun masih sedikit peminatnya.

Dilihat dari faktor risiko terjadinya kanker salah satunya adalah usia. Contohnya pada penderita kanker servix, kerentanan terjadi pada usia lebih muda, hal ini terjadi akibat sel kolumnar serviks lebih peka terhadap metaplasia selama usia dewasa maka wanita yang berhubungan seksual sebelum usia 18 tahun akan berisiko terkena kanker serviks lima kali lipat. Tidak hanya usia pertama saat melakukan hubungan seksual tetapi jumlah partner seksualpun merupakan faktor risiko kuat untuk terjadinya kanker serviks (Rasjidi, 2009). Kejadian ini berhubungan dengan keadaan di Arjasari, karena meskipun perkembangan zaman yang sudah pesat namun masih ada warga yang memiliki tradisi untuk menikahkan anaknya bahkan pada usia sangat muda atau sebelum 18 tahun.

Hal peningkatan pengetahuan juga ada faktor kecenderungan tingkat pendidikan peserta, didalam tabel disebutkan banyaknya peserta pada tingkat pendidikan SMA dan sederajat lainnya. Pada posisi kedua adalah SD yaitu sebanyak 17 peserta atau 28,3\%. Dari tingkat pendidikan peserta yang hadir, para peserta memiliki rasa penasaran yang tinggi, khususnya mengenai Ca Serviks ini. Sehingga selama berjalannya acara para peserta banyak yang bertanya seputar Ca serviks. Salah satu tujuan dari penelitian ini juga adalah meratakan informasi yang dimiliki warga di Desa Arjasari ini. Sehingga tidak hanya wanita dengan lulusan sekolah tinggi saja yang mengetahui tetapi seluruh lapisan masyarakat mengetahui tentang Ca serviks dan salah satu luarannya adalah masyarakat menjadi lebih concern terhadap pencegahan kanker pada keluarga dan masyarakatnya sendiri.

Namun menjadi hal yang dievaluasi adalah masih sedikitnya peserta yang hadir padahal sebelumnya peserta yang daftar sudah banyak. Hal ini disebabkan karena kurangnya persiapan dari pihak PKM dalam mengumumkan acaranya, jadi banyak wanita yang tibatiba tidak bisa hadir karena ada agenda lain.

Secara umum, berikut adalah data evaluasi proses Pendidikan kesehatan.Kegiatan utama dilakukan pada tanggal 16 September 2017, yaitu melakukan kegiatan penyuluhan dan deteksi dini kanker serviks yang dilakukan di Gor Desa Lebakwangi. Para peserta sangat antusias dalam menyambut kegiatan tersebut, dari hari sebelumnya didapatkan150 peserta yang mendaftar. Tetapi karena satu dan lain hal pada saat acara yang hadir hanya setengahnya saja atau 60 peserta saja.

Intervensi melalui kegiatan ceramah dan konseling dilakukan untuk meningkakan kemampuan literasi masyarakat. Karena sesuai dengan tujuan dari pendidikan kesehatan adalah untuk mengubah perilaku masyarakat yang tidak sehat menjadi sehat. Tujuan ini bisa dicapai karena manusia dapat belajar dan berubah. Sasaran dari kegiatan ini pun adalah masyarakat umum dengan berorientasi pada masyarakat pedesaan dan masyarakat kelompok tertentu yaitu adalah wanita 
baik remaja ataupun dewasa (Susilo, 2011).

Metode pada saat penyuluhannya dikombinasi antara metode caramah dan konseling (Notoatmojo, 2012). Metode ceramah dan konseling dilakukan oleh dosen-dosen Fakultas Keperawatan secara bergantian. Kegiatan pretest dan posttest ini digunakan untuk mengukur apakah pemberian materinya efektif atau tidak. Berdasarkan hasil pre-test dan post-test yang telah dilakukan pada peserta didapatkan hasil bahwa jumlah peserta yang mendapatkan nilai tinggi lebih banyak pada saat pre-test, sedangkan jumlah yang mendapatkan sedang paling banyak adalah pada saat post-test. Hal ini terjadi karena banyaknya hal, beberapa peserta tidak mengisi pada saat pre-test karena datang terlambat, sedangkan peserta yang tidak mengisi post-test lebih banyak karena pulang duluan dengan alasan pribadi. Faktor lainnya yang mempengaruhi adalah kurang efektifnya waktu, karena pada saat pre-test para peserta masih fresh untuk mengerjakan soalnya. Sehingga didapatkan hasil adanya perbedaan antara nilai pre-test dan post-test.

Pengetahuan kesehatan (health knowledge) mencakup apa yang diketahui oleh seseorang terhadap cara pemeliharaan kesehatan. Pengetahuan merupakan faktor predisposisi yang mempermudah terjadinya perubahan perilaku, termasuk perilaku kesehatan (Green, 2000). Pendidikan kesehatan sebagai pendekatan terhadap faktor perilaku kesehatan berhubungan dengan tingkat pengetahuan dan sikap individu seseorang. Proses pendidikan kesehatan dipengaruhi oleh beberapa faktor mulai dari materi atau pesan yang disampaikan, alat bantu atau media yang dipakai, metode yang digunakan serta fasilitator atau petugas yang melakukan promosi kesehatan (Notoatmodjo, 2012).

Usaha-usaha untuk mencegah meningkatnya jumlah penderita kanker salah satunya dengan cara meningkatkan kemampuan literasi masyarakat. Pendidikan kesehatan dengan metode kombinasi ceramah, dan konseling merupakan pendekatan individual melalui proses belajar sesuai dengan karakteristik masyarakat. Dalam penelitian Ririn Puspandari, dkk. (2012) disebutkan peran instruktur dalam proses belajar melibatkan tiga langkah. Model ini dapat "hidup" dipengaruhi instruktur atau fasilitator, media massa seperti televisi, film, program pelatihan berbasis komputer serta menjadi contoh simbolis melalui testimoni. Keuntungan model ini dapat dilihat lebih dari sekali oleh peserta pembelajaran. Dengan mempertimbangkan perilaku, model yang tepat diberikan kepada peserta pembelajaran dengan menciptakan lingkungan belajar yang terbaik dan kaya akan contoh.

Penelitian ini memanfaatkan dua metode merupakan cara atau pendekatan dalam menyampaikan informasi. Jenis metode dalam penelitian ini menggunakan kombinasi berupa ceramah dan konseling. Metode pembelajaran perlu dikombinasikan karena tidak ada metode yang paling baik dan bisa berdiri sendiri agar bisa diterapkan sesuai dengan sasaran yang diharapkan (Maulana, 2013).

Sasaran dalam penelitian ini adalah ibu ibu perwakilan masing-masing keluarga yang berusia dewasa melalui kegiatan pertemuan kelompok masyarakat. Intervensi pendidikan kesehatan kombinasi dengan konseling bisa termasuk metode pembelajaran individu, umumnya dengan berhadapan langsung sehingga materi yang diberikan berfokus pada pengalaman-pengalaman kehidupan. Hal ini memungkinkan responden akan lebih paham materi yang diberikan dan lebih leluasa bertanya jika ada hal yang belum dimengerti.

Faktor lain yang mempengaruhi peningkatan literasi adalah karakteristik dari individu masyarakat itu sendiri. Umur responden adalah umur individu yang terhitung antara 26 sampai 65 tahun. Usia 
ini termasuk pada tahap dewasa. Usia dewasa merupakan tahap seseorang mencapai kematangan fisik dan psikososial, dan kognitif. Individu yang dewasa merasa nyaman dengan persepsi dan pengetahuan yang dimiliki, terbuka menerima saran dan kritik, berusaha menyelesaikan masalah, serta mau mengambil keputusan terhadap masalah yang dihadapi (Potter \& Perry, 2005).

\section{KESIMPULAN DAN SARAN}

Peningkatan pengetahuan pada responden yang tidak mengalami peningkatan bisa dipengaruhi oleh kondisi internal dan eksternal individu. Faktor eksternal meliputi lingkungan keluarga, lingkungan sekitar, pengaruh teman dan instrumental (kondisi tempat dan waktu). Sedangkan faktor internal adalah psikologis dan fisiologis seperti tingkat perhatian, minat, daya konsentrasi, emosi dan kelelahan (Maulana, 2013). Pada pendidikan kesehatan dengan kombinasi metode ceramah, dan konseling terdapat beberapa hal yang dapat mengganggu tingkat konsentrasi individu diantaranya adalah masyarakat yang masih pengaruh lingkungan dan individu dalam kondisi lelah mengikuti proses penelitian dan kondisi ruang yang tidak terlalu kondusif, baik dari pencahayaan, maupun ventilasinya.

\section{DAFTAR PUSTAKA}

American Society of Clinical Oncology. (2014). Palliative Care Improving Quality of Life for Patients and Families. America.

Andrew. (2004). Effect of Two Educational Interventions on Knowledge and Attitudes Towards Electroconvulsive Therapy. Journal of ECT, 20.

Baggot, R. B., Kelly, K. P., Fochtman, D., \& Folley, G. (2001). Nursing care of children and adolescent with cancer, 3rd Ed. Pennsylvania: W.B Saunders Company.

Baradero, M., dkk. (2008). Seri Asuhan Keperawatan pada Klien Kanker. Jakarta: EGC.

Breast Cancer - UK. (2001). Mortality statistics: Cancer Reasearch UK. Available from: http://info.cancerresearchuk.org/cancer stats/types/breast/mortality/

[Accessed: 27 May 2012].

Depkes RI. (2011). Press release hari kanker anak sedunia. Diperoleh dari http://www.tv1.com/press_release hari _kanker_anak_sedunia_html tanggal 26 Februari 2011.

Doyle, H. \& MacDonald. (2003). Oxford Textbook of Palliative Medicine, 3rd ed. Oxford Medical Publications (OUP).

Effiong \& Effiong. (2012). Palliative care for the management of chronic illness: a systematic review study protocol. British Medical Journal Publishing Group, 2(3).

\begin{tabular}{ccr}
$\begin{array}{c}\text { Gatot, D. } \\
\text { dini }\end{array}$ kanker & $\begin{array}{r}\text { Deteksi } \\
\text { anak. } \\
\text { dari }\end{array}$ \\
$\begin{array}{l}\text { Diperoleh } \\
\text { http://www.dinkesjabar.go.id/info/dete }\end{array}$ \\
\hline $\begin{array}{ll}\text { ksi_dini_kanker_anak/html } & \text { tanggal }\end{array}$ \\
\hline 12 Desember 2010.
\end{tabular}

Globocan. (2008). International Agency for Research on Cancer (IARC). Available at:http://globocan.iarc.fr/factsheets/can cers/breast.as.

Hakkarainen, P. (2009). Designing and Implementing A PBL Course on Educational Digital Video Production : Lesson Learned from A DesignBased Research. Education Technology Research Development 
NERS: Jurnal Keperawatan, Volume 13, No. 1, Maret 2017, (Hal. 1-9)

Iryanti. (2003). Pengaruh pendidikan kesehatan reproduksi melalui metode peer education terhadap pengetahuan dan sikap remaja dalam pencegahan KTD. Yogyakarta : Tesis Universitas Gajahmada.

Karout, N. (2012). Impact of Health Education on Community Knowledge, Attitudes and Behaviour Towards Solid Waste Management in Al Ghobeiry, Beirut. Eastern Mediterranean Health Journal, EMHJ, $18(7)$.

Kurniawan, D.E. (2012). Perbedaan Pengaruh Penyuluhan Kesehatan Menggunakan Media Visual dan Media Audiovisual terhadap Perubahan Sikap Membuang Sampah pada Siswa di SMPN 1 Balung Kabupaten Jember. Jurnal Program Studi Ilmu Keperawatan, Fakultas Kedokteran Universitas Brawijaya.

Listyowati, D. (2012). Pengaruh Intervensi Pendidikan Kesehatan terhadap Pengetahuan, Sikap, dan Praktik Cuci Tangan Pakai Sabun pada Siswa Kelas 5 di SDN Pengasinan IV Kota Bekasi Tahun 2012. FKM, UI

Kepmenkes RI Nomor: 812/ Menkes/ SK/ VII/ 2007 tentang Kebijakan Perawatan Palliative. Menteri Kesehatan Republik Indonesia.

Kepmenkes RI tahun 2013 tentang Pedoman Teknis Pelayanan Paliatif Kanker. Menteri Kesehatan Republik Indonesia.

Kimman, M., Norman, R., Jan, S., et al. (2012). The burden of cancer in member countries of the Association of Southeast Asian Nations (ASEAN). Asian Pac J Cancer Prev, 13, 411-20.

$$
\text { (2010). Promosi }
$$

kesehatan teori dan aplikasi, edisi revisi. Jakarta : Rineka Cipta.
National Cancer Institute. (2010). Surveillance, epidemiology and end result (SEER). Diperoleh melalui Www.seer.cancer.gov/canque/incidenc e.html tanggal 11 Mei 2011.

(2009). A Snapshot of pediatric cancer. Diperolehmelalui http://www.cancer.gov/aboutnci/servin gpeople/cancer-snapshot tanggal 10 Januari 2011.

Palliative Expert Group. (2005). Therapeutic Guidelines Palliative Care, version 2, Therapeutic Guideline Limited. Melbourn.

Polit, D. F., \& Beck, C. T. (2008). Nursing research: Generating and assessing evidence for nursing practice, $8^{\text {th }}$ ed. Philadelphia: Lippincott Williams \& Wilkins.

Price, S. A., \& Wilson, L. M. (2005). Patofisiologi: Konsep klinis prosesproses penyakit. Jakarta: EGC. Pusat Data dan Informasi. 2015. Situasi Penyakit Kanker. Kementerian Kesehatan Republik Indonesia.

Suhag, V. (2005). Palliative Therapy in Cancer Patients: An Overview.

Sulistyowati, L. S. (2011). Promosi Kesehatan di Daerah Bermasalah Kesehatan. Kementerian Kesehatan Republik Indonesia.

Vella-Brincat, J, Macleod, A.D, MacLeod, R. (2008). The Palliative Care Handbook, Guidelines for Clinical Management and Symptom Control, 4th ed. The Caxton Press.

WHO. (2014). Global Atlas of Palliative Care at the End of Life. World Health Organization.

WHO (2007). WHO guide for effective programmes: Palliative Care. ed. Geneva. World Health Organization. 
NERS: Jurnal Keperawatan, Volume 13, No. 1, Maret 2017, (Hal. 1-9)

WHO (2002). National Cancer Control Programmes: Policies and Managerial Guidelines, $2^{\text {nd }}$ ed.Geneva, World Health Organization. 